\title{
COMPARISON OF GAS CHROMATOGRAPHIC AND GRAVIMETRIC METHODS FOR QUANTIZATION OF TOTAL FAT AND FATTY ACIDS IN FOODSTUFFS
}

\author{
Sabria Aued-Pimentel*, Mahyara Markievicz Mancio Kus, Edna Emy Kumagai, Valter Ruvieri e Odair Zenebon \\ Divisão de Bromatologia e Química, Instituto Adolfo Lutz, Av. Dr. Arnaldo, 355, 01246-902 São Paulo - SP, Brasil
}

Recebido em 4/1/09; aceito em 19/7/09; publicado na web em 25/11/09

\begin{abstract}
Different methods to determine total fat (TF) and fatty acids (FA), including trans fatty acids (TFA), in diverse foodstuffs were evaluated, incorporating gravimetric methods and gas chromatography with flame ionization detector (GC/FID), in accordance with a modified AOAC 996.06 method. Concentrations of TF and FA obtained through these different procedures diverged $(\mathrm{p}<0.05)$ and TFA concentrations varied beyond $20 \%$ of the reference values. The modified AOAC 996.06 method satisfied both accuracy and precision, was fast and employed small amounts of low toxicity solvents. Therefore, the results showed that this methodology is viable to be adopted in Brazil for nutritional labeling purposes.
\end{abstract}

Keywords: total fat; fatty acids; nutritional labeling.

\section{INTRODUCTION}

Nutritional labeling information is one of the employed strategies by the World Health Organization to avoid chronic disease. ${ }^{1,2}$ Since inadequate ingestion of both saturated and trans fatty acids increases cardiovascular diseases risk, ${ }^{3}$ the attention to dietary fat has increased either in health aspects and in analytical determination. Brazilian legislation demands the declaration of total fat (TF), saturated (SFA) and trans fatty acid (TFA), among other nutrients, on the label of packed foods (RDC 360/03 ANVISA/MS). ${ }^{4}$ To commit to such legislation, laboratories must be able to verify, by means of analysis, the contents declared on labels. ${ }^{5}$

Total fat and fatty acid determination in food products comprises several steps and, depending on the type of food, laws and analysis procedures, different results should be generated. ${ }^{6,7}$ Food lipids are constituted mainly, more than $90 \%$, by triacylglycerol (TAG), which are esters of fatty acids and glycerol. Phospho- and glycolipids, sterols, waxes and free fatty acids are minor components of food fat. When not free, fatty acids are linked in such compounds by ester or amide bonds to other molecules but glycerol. ${ }^{8}$

Total fat determination requires a quantitative extraction of all lipid compound classes and the breakage of bonds and interactions with nonfat compounds. As various energy amounts are involved (interactions range from van der Waals to ionic forces), appropriate solvents should be chosen for each case. The fat content of food has traditionally been determined by extraction with organic solvents, followed by extract drying and gravimetric determination. Non-polar organic solvents such as chloroform and $n$-hexane are used for disrupting hydrophobic and ion-dipole interactions (e.g. lipid hydrophobic chain and non-polar amino acids) whereas polar organic solvents with high dielectric constant, such as methanol, for breaking hydrogen bonds (e.g. non-lipid compounds and lipid hydroxyl, carboxyl or amino groups). ${ }^{6-8}$

Several methods have been reported in the literature and are indicated for specific food matrices. Fat extraction based on Soxhlet method (reflux with diethyl ether, petroleum ether or $n$-hexane) extracts neutral lipid, such as triacylglycerols, in raw cereal, nuts, meat products, etc. ${ }^{6,9,10}$

Methods employing the mixture of solvents chloroform/methanol (Bligh and Dyer or Folch, Lees and Stanley) have been extensively used for total lipid quantization in biological samples (meat products,

\footnotetext{
*e-mail: spimente@ ial.sp.gov.br
}

fish). They are recommended for total fat determination in composite foods and foods for which methods of analysis are not specified. ${ }^{6,11-13}$ These methods have been chosen as reference to extract fat for fatty acid determination and other characterization, because of their mild conditions of extraction and the capacity of the mixture of solvents to extract different lipid classes without changing the structure of these molecules. ${ }^{6,12}$ However, the extraction efficiency is strongly influenced by experimental variants, such as solvent-sample proportion, time and intensity of whirling in the procedures, among others. ${ }^{8,13}$

Several food samples (flour, baked products, processed cheese, etc) should be pre-treated by acid hydrolysis methods before fat extraction of neutral lipid with ether. Digestion with hydrochloric acid liberates fatty acids from glycerides, glyco- and phospholipids, and sterol esters and also hydrolyzes the protein content present in such samples. ${ }^{6,10-12}$ Yet, this procedure also extracts non-fat material such as glycerol, low molecular weight carbohydrates and others. Therefore, results using these methods may be higher than true fat values. ${ }^{12}$

A previous alkaline treatment assists extraction of fat in many dairy products, including cheese. Usually ammonium hydroxide is employed to disperse fat emulsion, neutralize remaining acid and solubilize protein (casein) prior to extraction with ether. ${ }^{6}$

Concerning fatty acid (FA) quantization by GC/FID, a critical point is the expression of FA concentration in gram percent of the food sample. The most simplified approach to express the concentration of the FA contents, without more complex schedules or high purity standards, has been achieved by area normalization, employing theoretical factors to convert area percent of methyl esters into gram of the respective fatty acid in gram percent of the food sample. This factor incorporates the contribution of fatty acids from each class of lipids in a specified group of products, e.g, for egg the conversion factor is 0.830; for dairy products, 0.945 ; and for nuts, $0.956 .^{10,14}$ Quantitative methods by normalization have the disadvantage of error propagation, however, because results are strongly related thereto.

A more accurate quantization of FA has been developed with internal standards and a flame ionization detector (FID) response correction factor. The purpose of which is to correct the non-linearity of the FID response to the mass of fatty acid methyl esters (FAMEs). Theoretical response correction factors are calculated by a formula considering the detector response proportional to the relative percentage of carbons in diverse molecules. The application of this method also requires an optimization of instrumental conditions. 
Thus, an empirical correction factor (ECF), which takes account of the chemical and instrumental deviations, is determined by means of calibration with pools of standards. ${ }^{15,16}$ The employment of the theoretical, or the empirical, correction factor in the calculations depends on the standard method recommendation. ${ }^{6,17}$

Both approaches, as well as the laws governing nutritional labeling of foods, are new themes, whereby definitions about which lipid contents should figure on the label have not been uniformed yet, nor analytical methods to be adopted, counting those in Brazilian laboratories.

According to Brazilian legislation, total fat (TF), for purposes of nutritional labeling, is defined as the total amount of substances of vegetable or animal origin, constituted by both triacylglycerol (TAG) and non-glyceride, such as phospholipids (PL). ${ }^{4}$ A number of methods are available for gravimetric analysis of fat as described above. ${ }^{6,7,9}$ United States (US) and Canada nutritional labeling legislation, on the other hand, has defined TF as the sum of fatty acids that originate from the different classes of lipids (mono-, di-, triacylglicerols, phospholipids and sterol esters), expressed as triacylglycerols. ${ }^{18}$ This definitions limited what is considered fat for nutritional labeling purposes. According to the three cited legislations, saturated, mono- or poli-unsaturated and trans fatty acids must be expressed as free fatty acids.

In order to satisfy the chemical definition of fat stated in the US legislation, hydrolytic methods were developed to extract fat and fatty acids (FA) from food and then to determine FA contents by GC/FID. Total fat (TF) determined by GC/FID AOAC 996.06 method was calculated through a mathematical formula. A condensation model of three fatty acids molecules, originated from the hydrolysis of mono-, di- or triacylglycerol, phosphoolipid and sterol esters of foods, with a molecule of glycerol is demanded to calculation.

The restriction in the definition of fat, thus, propitiated method standardization, aiming at the same time to decrease laboratories results discrepancies. AOAC method $996.01^{6}$ was developed for cereal products containing between 0.5 to $13 \%$ fat, whereas AOAC $966.06^{6}$ has been recommended for foods in general. Modifications have been proposed to improve the analytical conditions ${ }^{19}$ and to optimize the determination of trans fatty acids..$^{20,21}$ The applicability of those methods has been confirmed for several food matrices with variable amounts of fat. ${ }^{20,22-24}$

Considering the aspects discussed above, this work aimed to compare analytical procedures employed in Brazilian laboratories and the official recommended methods for nutritional labeling of total fat (TF), saturated (SFA), polyunsaturated PUFA and trans (TFA) fatty acids contents in several foodstuffs, as well as to verify whether the determined values were in agreement with Brazilian legislation tolerance $( \pm 20 \%)$. Additionally, analytical procedures were evaluated considering, besides method performance, cost, rapidity and reduction of both solvent volume and toxicity.

\section{EXPERIMENTAL}

\section{Material}

Food reference samples were purchased from American Oil Chemists Society in Nutritional Labeling series 2004/2005 and 2005/2006. The samples analyzed were: egg, milk, cheese, and vanilla pudding (AOCS samples) as well as one commercial chocolate biscuit sample, elaborated with partially hydrogenated vegetable fat (PHVF), the fat and fatty acid content of which were expressed on its food labeling nutrition facts.

\section{Reagents, solvents and standards}

Reagents and solvents for fat extraction and fatty acid methyl ester (FAME) preparation were of analytical grade: ethanol, methanol, hydrochloric acid $8.3 \mathrm{~mol} \mathrm{~L}^{-1}$, ethyl ether, petroleum ether, methanolic sodium hydroxide $(\mathrm{NaOH})$ solution $0.5 \mathrm{~mol} \mathrm{~L}^{-1}$, ammonium chloride $\left(\mathrm{NH}_{4} \mathrm{Cl}\right)$, saturated sodium chloride $(\mathrm{NaCl})$ solution $(26 \% \mathrm{w} / \mathrm{v}) . n$ Hexane for preparing standards solutions and GC analysis was of chromatographic grade.

The following FAME standards were used: mixture of 37 FAMEs from 4 to 24 carbon atoms (Supelco Inc. and Bellefonte, PA, USA) mixture of cis/trans FAME isomers of 18:2 and 18:3 (Sigma Chemical Co, St Louis, MO); individual FAME standards purchased from Sigma (about 99\% purity): elaidic (18:1 9t), trans vacenic (18:1 $11 t), 18: 17 c, 18: 112 c$, conjugated linoleic acid (CLA) (18:2 9c11t and $18: 210 t 12 c)$.

The internal standards (IS), triacylglycerols (TAGs) and FAMEs 11:0 and 13:0, were purchased from Sigma Chemical Co, St Louis, MO.

\section{Lipid standards solution}

TAGs and FAMEs 11:0 and 13:0 (IS) solutions were prepared by weighing $250 \mathrm{mg}$ into a 50 or $100 \mathrm{~mL}$ volumetric flask, dissolving and completing the flask volume with $n$-hexane.

Individual standard solutions were prepared transferring the glass vial contents ( 25 to $100 \mathrm{mg}$ ) to a 25 or $50 \mathrm{~mL}$ volumetric flask with the aid of $n$-hexane. 1.0 mL of FAME 13:0 standard solution was added and the volume was completed with $n$-hexane.

The FAME mixture solutions (37 standards and cis/trans isomers) were prepared by transferring the contents to a $25 \mathrm{~mL}$ volumetric flask and completing the volume with $n$-hexane.

\section{Methods}

\section{Total fat by gravimetric determination}

The gravimetric methods for TF followed the Métodos FísicoQuímicos para Análise de Alimentos do Instituto Adolfo Lutz ${ }^{10}$ and AOAC methods. ${ }^{6,21}$ Briefly, the procedures were the followings:

Soxhlet method with ethyl ether as extraction solvent (during 6 h) ${ }^{10}$ was applied to powder egg and chocolate biscuit.

AOAC 963.15: the sample (milk, cheese, vanilla pudding and chocolate biscuit) was digested by refluxing with $\mathrm{HCl} 4.5 \mathrm{~mol} \mathrm{~L}^{-1}$ for $30 \mathrm{~min}$. The residue was filtrated and washed with water until $\mathrm{pH}$ between 6-7. The residue was dried and the fat extracted by refluxing with petroleum ether during $6 \mathrm{~h}$.

AOAC 925.32: the egg sample was digested with $\mathrm{HCl} 9.8 \mathrm{~mol}$ $\mathrm{L}^{-1}$. The fat was extracted from the residue with a mixture of diethyl and petroleum ether $(1: 1)$.

Bligh and Dyer ${ }^{25}$ method: the sample (milk, cheese, egg, and chocolate biscuit) was homogenized with a $1: 2: 0.8$ chloroform:methanol:water mixture for $2 \mathrm{~min}$ and followed by $2: 2: 1.8$ chloroform:methanol:water mixture for $5 \mathrm{~min}$. The chloroform layer was separated and the solvent removed.

Folch, Lees and Stanley ${ }^{26}$ method: a volume of 2:1 chloroform:methanol in the proportion of 20 times the sample weight was added to the sample (vanilla pudding). The mixture was homogenized by $3 \mathrm{~min}$ and filtered. The water layer was extracted twice more with 2:1 chloroform:methanol. The crude extracts were washed with water $(0.2$ volume $)$ and the chloroform phases, separated. The solvent layers were combined.

AOAC 989.05 (Roese Gottlieb): milk sample was hydrolyzed with $2 \mathrm{~mL} \mathrm{NH}_{4} \mathrm{OH} 58 \%$ and fat extracted from the residue with 3 portions of diethyl and petroleum ether (1:1).

AOAC 933.05: cheese sample was hydrolyzed with $1 \mathrm{~mL}$ of $\mathrm{NH}_{4} \mathrm{OH} 58 \%$ in a heated water bath for $10 \mathrm{~min}\left(70-80{ }^{\circ} \mathrm{C}\right)$. The solution was neutralized by addition of $10 \mathrm{~mL}$ of $\mathrm{HCl} 12 \mathrm{~mol} \mathrm{~L}^{-1}$, prior to heating by $20 \mathrm{~min}$. After cooling to room temperature, fat was extracted with 3 portions of diethyl and petroleum ether (1:1). 
In all methods the organic solvent was removed in an evaporator with $\mathrm{N}_{2}$ steam and the residue dried to constant weight.

\section{Total fat from fatty acid composition (GC-FID) - modified AOAC 996.06 method}

The total fat (TF) content in foodstuffs was also determined by AOAC method 996.06, ${ }^{6}$ from their fatty acid composition. Food samples, excluding dairy products and cheese, containing between 100 to $200 \mathrm{mg}$ of fat were weighed into $100 \mathrm{~mL}$ corked centrifuge tubes. The internal standard, TAG 13:0 and TAG 11:0, solutions ( $2 \mathrm{~mL}$ ) were added ( $5 \mathrm{mg} \mathrm{mL}^{-1}$ in $n$-hexane) as well as $2 \mathrm{~mL}$ of ethanol $95 \%$. Samples were hydrolyzed with $8.3 \mathrm{~mol} \mathrm{~L}^{-1} \mathrm{HCl}(10 \mathrm{~mL})$ in a warm-bath (70 to $80{ }^{\circ} \mathrm{C}$ ) for $40 \mathrm{~min}$. Ethanol $95 \%$ was added $(10 \mathrm{~mL})$. The tubes were vortex mixed and cooled in water-bath to room-temperature. The contents of the tubes were transferred to a $250 \mathrm{~mL}$ separator funnel and fat extracted with 3 aliquots of ethyl ether and petroleum ether (1:1). Ether extract was filtered through fat-free paper in a $150 \mathrm{~mL}$ glass. The solvent was dried with nitrogen and the extracted fat was methylated and analyzed by CG/FID. TF was calculated as the sum of individual fatty acids expressed as equivalent TAG. The procedure described above involves modifications proposed by Satchithamandam, Fritsche, Rader ${ }^{27}$ and some implemented in this work, such as the substitution of borum trifluoride $\left(\mathrm{BF}_{3}\right)$ methanolic methylation reagent for Hartman and Lago method, ${ }^{28}$ modified by Maia and Rodrigues-Amaya. ${ }^{29}$

AOAC 996.06 method by acid hydrolysis was developed to be used for foodstuffs, excluding milk products and cheese. For these products some of the steps were modified. The samples were dissolved in warmed distilled water ( 2 to $4 \mathrm{~mL}$ ), and the internal standards were added. After the addition of $2 \mathrm{~mL}$ ethanol 95\%, $2 \mathrm{~mL}$ of $\mathrm{NH}_{4} \mathrm{OH}$ $58 \%(\mathrm{w} / \mathrm{w})$ were added to the tubes and these were put in water bath heated between 70 to $80{ }^{\circ} \mathrm{C}$ for $10 \mathrm{~min}$. As for the cheese samples, after the above-described basic hydrolysis step, $10 \mathrm{~mL}$ of $\mathrm{HCl} 12 \mathrm{~mol}$ $\mathrm{L}^{-1}$ were added, and the tubes were heated in water bath to ebullition for $20 \mathrm{~min}$. The other steps were carried out according to the previous procedure after the addition of $10 \mathrm{~mL}$ ethanol $95 \% .{ }^{21}$

\section{Fatty acid determination by GC/ FID analysis}

Fatty acid methyl esters (FAMEs), prepared by Hartman and Lago modified method, were analyzed by gas chromatography on a Shimadzu gas chromatograph (GC 17A model), with flame ionization detector (FID), using a capillary fused silica column with a cyanopropyl polysiloxane stationary phase ( $\mathrm{SP}^{\mathrm{TM}}$ - 2560, $100 \mathrm{~m}$ x $0.25 \mathrm{~mm}$ id, $0.20 \mu \mathrm{m}$ film thickness - Supelco Inc. Bellefonte, PA, USA). The chromatographic conditions were optimized through analyses of vegetable oil and partially hydrogenated vegetable fat (PHVF) samples, with reference values for fatty acids, including for trans fatty acids. ${ }^{21}$

The determined optimal conditions were as follow: programmed column temperature from 45 up to $175^{\circ} \mathrm{C}\left(13^{\circ} \mathrm{C} \mathrm{min}-1\right.$ ); then up to $215{ }^{\circ} \mathrm{C}\left(4{ }^{\circ} \mathrm{C} \mathrm{min}{ }^{-1}\right)$; stationary at $215^{\circ} \mathrm{C}$ for $35 \mathrm{~min}$; injector and detector temperature: $250^{\circ} \mathrm{C}$; carrier gas: hydrogen; column pressure: $175 \mathrm{kPa}$. The compounds were identified by standards co-injection and relative retention time to FAME 13:0 (internal standard).

\section{Calibration}

Appropriate response factors were employed to convert area percent of FAME into true weight percent. The corrected response for each FAME were calculated experimentally, expressed in terms of the response to methyl tridecanoate, or theoretically, expressed in terms of the response to methyl palmitate. ${ }^{10}$

\section{Calculation}

Three calculation methods to express fatty acid concentration in $\mathrm{g} / 100 \mathrm{~g}$ were compared: 1) fatty acid determination by the addition of a FAME 13:0 as internal standard, after lipid extraction; ${ }^{10} 2$ ) mass percentage determination for each FA by normalization, which resulted from lipids percentage and theoretical conversion factors, comprehending the transformation of FAME into FA and the contribution of each lipid fraction from different foods (triacylglycerols and phosfolipids) in providing FA (e.g., egg: 0.83; milk: 0.945; oleaginous seeds: 0.956$) ;{ }^{10,14} 3$ ) TF and FA quantization by modified ${ }^{21}$ AOAC 996.06 method, ${ }^{6}$ as described above, in which the mass of each FAME was determined as the corresponding TAG (Equation 3)

$$
\begin{aligned}
& M_{F A M E_{i}}=A_{F A_{i}} \frac{m_{T A G_{I S: 0}} 1,0059 K_{F A_{i}}^{\prime}}{A_{F A_{I S: 0}}} \\
& M_{F A}=M_{F A M E_{i}} f_{F A_{i}} \\
& M_{T A G_{i}}=M_{F A M E_{i}} f_{T A G_{i}}
\end{aligned}
$$

where: $\mathrm{M}_{\mathrm{FAMEi}}=$ weight of each fatty acid methyl ester (FAME); $\mathrm{A}_{\mathrm{FAi}}$ $=$ peak area of FAME " $i$ " in the test portion; $m_{\text {TAG13:0 }}=$ weight of the internal standard (IS) triacylglicerol (TAG) 13:0 added in the test portion; $1,0059=$ theoretical conversion factor for internal standard TAG to FAME; $\mathrm{K}_{\text {FAi }}=$ FID experimental response factor relate to FAME 13:0; ${ }^{10} \mathrm{~A}_{\mathrm{FAC} 13: 0}=$ Peak area of IS 13:0 in the test portion; $\mathrm{M}_{\mathrm{TAG}}$ $=$ amount of individual TAG in the test portion; $f_{\mathrm{TAGi}}=$ conversion factor for FAME to TAG; $f_{\mathrm{FAi}}=$ conversion factor for FAME to FA; $\mathrm{M}_{\mathrm{FA}}=$ weight of each fatty acid.

\section{Recovery}

Percentage recovery of quantification methods, by means of internal standards (TAG 13:0 or FAME 13:0), was evaluated by the addition of a second internal standard to the samples (TAG 11:0 or FAME 11:0). The efficiency of the Hartman and $\mathrm{Lago}^{28}$ methylation method, adapted to the AOAC 996.06 method, was evaluated by means of this recovery assay. The area of the standard added (both in the blank and in the samples) was monitored, and the TAG 11:0, or the FAME 11:0, recovery, calculated. Percent recovery is expressed through the ratio between experimental and theoretical values.

\section{Statistics}

The method precision was evaluated by relative standard deviation (\% RSD) (five repetitions) and its accuracy by comparisons with reference and experimental values (z-score), considering acceptable variations among inter laboratorial studies, as well as $20 \%$ around reference value. Variance analyses and Tukey tests were employed (5\% significance) ${ }^{30}$

\section{RESULTS AND DISCUSSION}

\section{Total fat and fatty acid determination in foodstuffs}

A variety of food products were analyzed (dairy products, egg, chocolate biscuit and vanilla pudding) and different methods were applied for each one, in accordance with official methods and the laboratories current practices. Although there are recommended methods for each food class, these are nowadays in evaluation because of new demands, such as the nutritional labeling information. The features of each sample, such as fat and moisture contents, addition of additives and the technological process it went through, could distinctively influence the performance of each method.

Results for the quantization of total fat (TF), saturated (SFA), polyunsaturated (PUFA) and trans fatty acids (TFA) contents are presented in Tables 1 to 5 , and consist of mean values $\left(n_{2}=5\right)$, stan- 
dard deviation (SD) and relative standard deviation (\% RSD). The reference values for each of the analyzed foods are also presented in its respective table.

\section{Dairy products (milk and cheese powder samples)}

Tables 1 and 2 present results for the TF, SFA, PUFA and TFA concentrations established by the different fat extraction methods and calculation modes, along with the reference mean value of AOCS inter laboratorial study for dairy products (milk and cheese, respectively).

The fat of dairy products contains mainly neutral lipid as TAG, with a great number and variety of fatty acids. ${ }^{12}$ Figure $1 \mathrm{~S}$, supplementary material, shows the FAME chromatogram of the analyzed milk fat.

In accordance with AOAC official methods, basic hydrolysis (milk and cheese - AOAC 989.05 / AOAC 933.05) and acid hydrolysis (cheese - AOAC 963.15) were employed to solubilize casein and digest other compounds to liberate the fat before extraction. However, due to the diversity of powder milk products, several laboratories have also been using previous acid hydrolysis for total fat determination, to guarantee a better recovery of the fat content.

Comparing the fat extraction methods, the one with a previous acid hydrolysis (AOAC 963.15) provided the highest fat contents for both milk and cheese samples and the lowest dispersion ( $\mathrm{n}=5, \%$ RSD $<1 \%$ ). This procedure, probably, also extracted non-fat material such as glycerol, low molecular weight carbohydrates and others. ${ }^{11,12}$ On the other hand, Bligh and Dyer and Roese Gottlieb (AOAC 989.05) extraction methods for milk and AOAC 933.05 extraction method for cheese gave lower results of total fat (Tables 1 and 2). No significant difference was observed between the results from Bligh and Dyer and Roese Gottlieb extraction methods for the milk sample. Total fat results for the cheese sample acquired through Bligh and Dyer and AOAC 933.05 methods had good agreement, too.

All these methods required several extraction steps for an adequate total fat recovery and the high content of fat in samples (milk about $30 \%$ and cheese, $40 \%$ ) probably contributed to decrease the rate of extraction. The Bligh and Dyer method has been indicated to extract fat in dairy products due to its mild conditions that prevent the loss of low molecular weight fatty acids. Nevertheless, its extraction efficiency is strongly influenced by experimental variants, such as the ratio of chloroform, methanol and water to the proportion $1: 2: 0.8$ and $2: 2: 1.8$, in the initial and final steps of extraction, respectively. ${ }^{12,13,25,26}$ Furthermore, modifications introduced in this experimental procedure contribute to divergent results from different laboratories. ${ }^{6,8,11-13}$ Additionally, the solvents employed, chloroform and methanol, are toxic. Chloroform is classified by International Agency for Research on Cancer (IARC) within $2 \mathrm{~B}$ group of possibly carcinogenic compounds. ${ }^{31}$

Concerning the FA determination, the values of total fat from the different gravimetric methods had great influence on FA values, once the total fat (or lipids) contents were employed in the calculation of fatty acid concentration. Acid hydrolysis procedures overestimated total fat contents and affected the reactive sites of the PUFA. ${ }^{6,12}$ AOAC 963.15 method resulted in the widest dispersion (\% RSD) of PUFA and TFA values and the lowest content of PUFA (Tables 1 and 2). As samples were hydrolyzed with $4.5 \mathrm{~mol} \mathrm{~L}^{-1}$ hydrochloric acid and boiled during $30 \mathrm{~min}$, such energetic conditions could promote the breakage and isomerization of double bonds.

Figure 1 (A and B, milk and cheese, respectively) shows the results dispersion for TF and FA from the different fat extraction methods and calculation modes, with regard to the reference mean (ordinate zero) of the AOCS inter laboratorial study. In some cases, data evidence variability greater than $20 \%$, mainly for TFA, which is beyond the range accepted by the Brazilian technical regulation over nutritional labeling. ${ }^{4}$

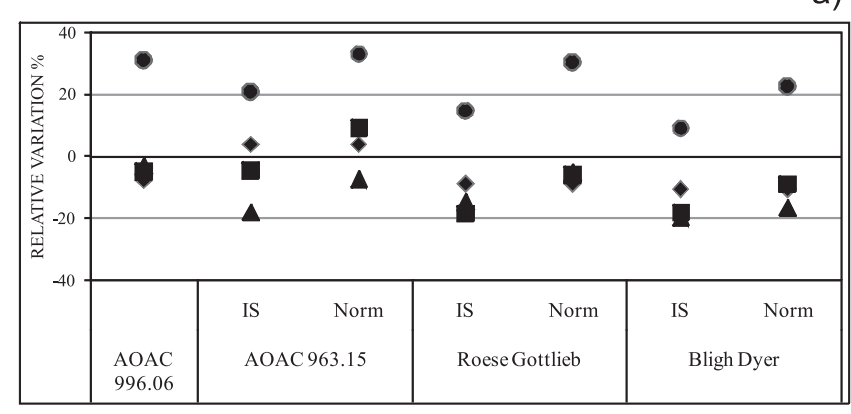

b)

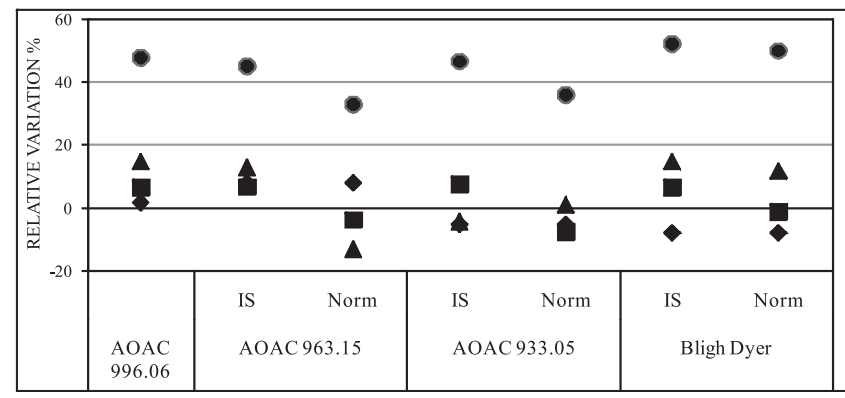

Figure 1. Relative percentage variations of experimental values, from different procedures, to the reference values (zero ordinate) of total fat $\bullet$ saturated $(S F A) \boldsymbol{\square}$, polyunsaturated (PUFA) $\boldsymbol{\Delta}$ and trans fatty acid (TFA) •. A) powder milk and B) powder cheese. IS: internal standard, FAME 13:0. Norm: normalization. AH: acid hydrolysis (AOAC 963.15); BH: basic hydrolysis (milk: 996.06 and Roese Gottlieb). MH:mix hydrolysis (cheese:AOAC 996.06 and $A O A C$ 933.05)

Considering the trans fatty acids (TFA), the total content for all methods was higher than the reference values. In the present study, besides the main 18:1 trans isomers ( $6 t$ to $12 t$ ) (Figure $1 \mathrm{~S}$ ), other trans isomers such as the major CLA (conjugated linoleic isomer, 18:2 $9 c, 11 t$ ) were included in total trans content, even though Brazilian nutritional labeling legislation does not specify which trans isomers should be included on label nutrition facts. ${ }^{4}$ The CLA major trans isomer contributed with about $1 \%$ of the total trans content in those dairy products (Tables 1 and 2). The inclusion of those isomers, the low contents ( 1 to $2 \%$ of TFA) in samples and the unequal analytical capacity to determine TFA in different laboratories probably contributed to the divergence in results.

\section{Powder egg sample}

Figure 2 shows that TF values in egg power, obtained by different methods, situated within the interval between $-2<\mathrm{z}<2$ (satisfactory range) considering the tolerance of $20 \%$. In contrast, for same procedures (fat extraction and FA quantization) the variability of SFA, PUFA and TFA values was greater than $20 \%$ when compared with the reference mean (ordinate zero).

Despite the fact that no significant difference ( $p>0.05)$ was observed among the results of total fat (TF) in power egg sample by different extraction methods (Table 3 ), the FA values displayed significant difference $(\mathrm{p}<0.05)$ among them (Table 3 and Figure 3 ). The values for TF determined by Soxhlet and AOAC 925.32 methods showed the lowest dispersion (\% RSD 1\%). TF by GC/FID AOAC 996.06 showed the highest dispersion probable due to the high content of fat (>40\%) which made total fat extraction more difficult.

Egg fat is mainly comprised by neutral lipids in the form of TAGs $(65 \%)$ and polar lipids in the form of phospholipids (30\%). ${ }^{32}$ The mixture of chloroform and methanol solvents, used in the Bligh and Dyer 
Table 1. TF, SFA, PUFA and TFA concentration values in powder milk reference sample (AOCS nutritional labeling series 2004/2005). Values for the different fat extraction methods as well as those described in the reference study are presented. For each extraction method, results obtained by distinct calculation modes (using internal standard or normalization)

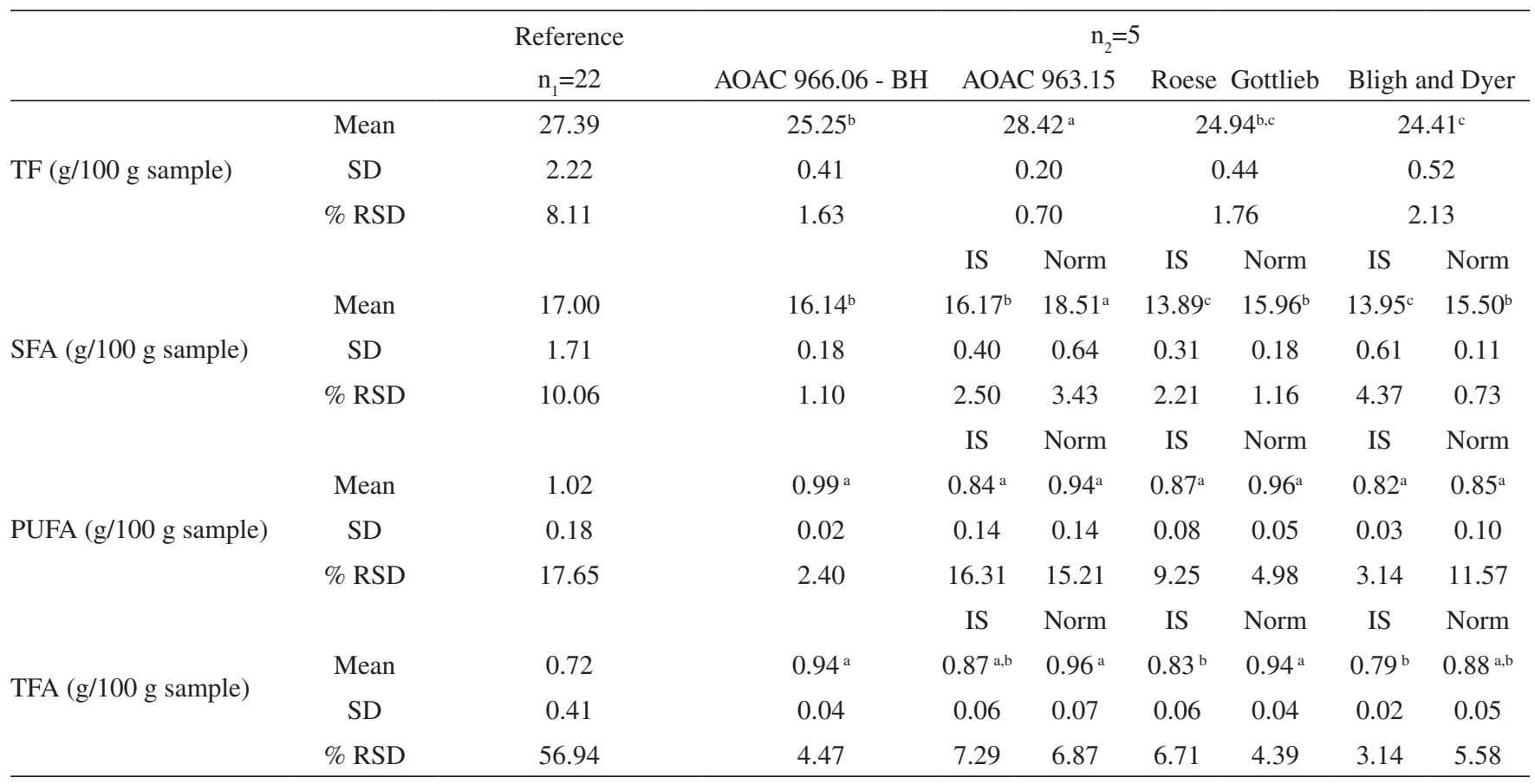

${ }_{\text {a,b,c }}$ Means with the same letter in the same line are not significantly different ( $\left.\mathrm{p} \leq 0.05\right)$. Theoretical factor for normalization (Norm): 0.945. IS: internal standard FAME 13:0. SD: standard deviation RSD: relative standard deviation. $\mathrm{n}_{1}$ : number of laboratories. $\mathrm{n}_{2}$ : number of repetitions. $\mathrm{BH}$ : basic hydrolysis.

Table 2. TF, SFA, PUFA and TFA concentration values in powder cheese reference sample (AOCS nutritional labeling series 2004/2005). Values for the different fat extraction methods as well as those described in the reference study are presented. For each extraction method, results obtained by distinct calculation modes (using internal standard or normalization)

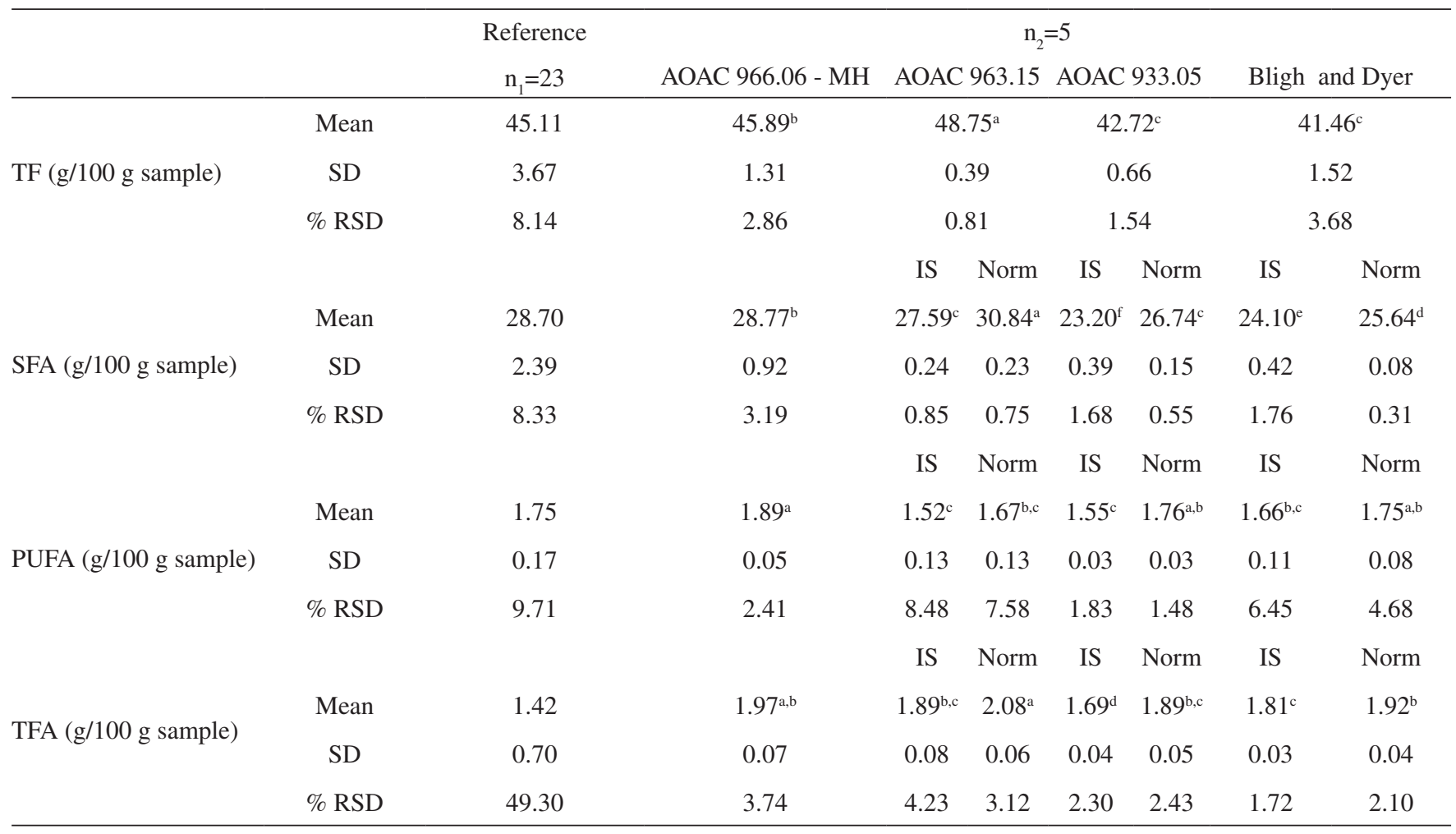

a,b,c,d,e, Means with the same letter in the same line are not significantly different ( $\mathrm{p} \leq 0.05)$. Theoretical factor for normalization (Norm): 0.945. IS: internal standard 
Table 3. TF, SFA, PUFA and TFA concentration values in powder egg reference sample (AOCS nutritional labeling series 2004/2005). Values for the different fat extraction methods as well as those described in the reference study are presented. For each extraction method, results obtained by distinct calculation modes (using internal standard or normalization)

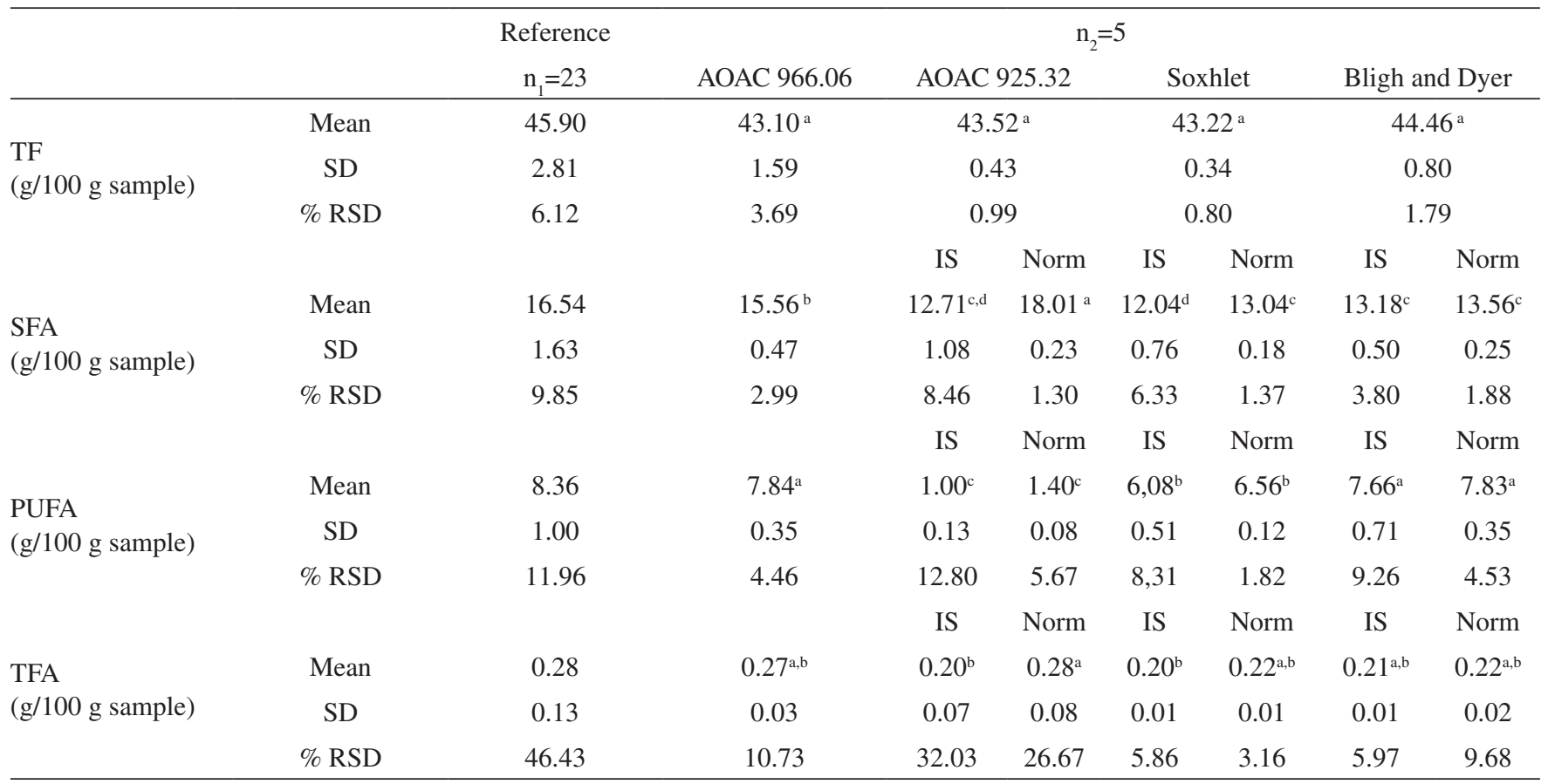

${ }_{a, b, c, d}$ Means with the same letter in the same line are not significantly different ( $\mathrm{p} \leq 0.05$ ). Theoretical factor for normalization (Norm): 0.830 . IS: internal standard FAME 13:0. SD: standard deviation RSD: relative standard deviation. $\mathrm{n}_{1}$ : number of laboratories. $\mathrm{n}_{2}:$ number of repetitions.

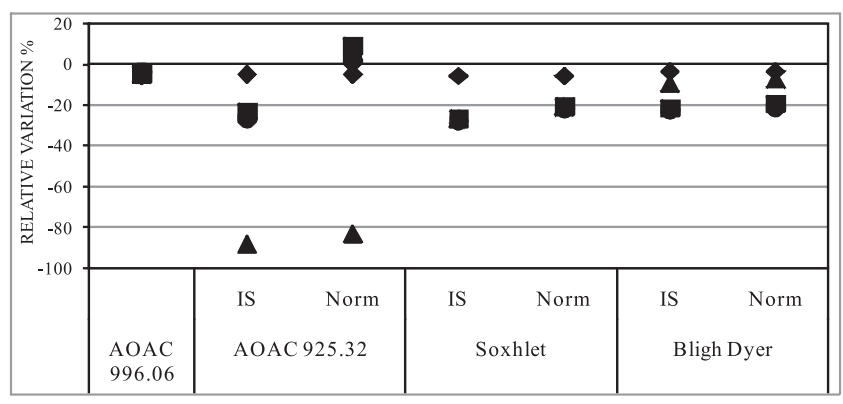

Figure 2. Relative percentage variations of experimental values of powder egg sample, from different procedures, to the reference values (zero ordinate) of total fat $\bullet$, saturated (SFA) $\mathbf{\square}$, polyunsaturated (PUFA) $\boldsymbol{\Delta}$ and trans fatty acid (TFA) •. IS: internal standard, FAME 13:0. Norm: normalization. AH: acid hydrolysis (AOAC 996.06; AOAC 925.32)

extraction method, has been proved appropriate to extract both neutral and polar lipids. Hence, such method displayed the best performance on extraction of egg fat. Table 3 shows that the contents of PUFA were the highest when the extraction was done by the mixture of chloroform and methanol solvents since egg phospholipids contain considerable quantities of PUFA 18:2. On the other hand, Soxhlet extraction method which employed ethyl ether as solvent extracted only neutral lipid and showed lower recoveries of TF and mainly PUFA. Fatty acids quantization results presented no significant difference $(\mathrm{p}>0.05)$ between calculation methods using internal standard (IS) and normalization (Norm) with theoretical conversion factors ( 0.830 for egg), especially when the extraction was made by the Bligh and Dyer method.

The lowest dispersion of SFA and PUFA results (\% RSD) (Table 3) were observed by Soxhlet and Bligh and Dyer methods when calculation was performed by area normalization. Still, results by area normalization are not so accurate and usually overestimate the contents. A wide dispersion of TFA results (\% RSD) was observed for all methods and the variability was above $20 \%$ the reference mean, probably because of the low TFA content in the egg sample.

Although no significant difference was observed for TF determined by the different methods (Table 3 ), the acid hydrolysis employing AOAC 925.32 method affected PUFA reactive sites. Figure 2 and Table 3 show the very low content of PUFA in powder egg sample after the extraction by AOAC 925.32 method. This procedure used more concentrated $\mathrm{HCl}\left(\sim 9.8 \mathrm{~mol} \mathrm{~L}^{-1}\right)$. Additionally, sample was boiled during $30 \mathrm{~min}$ in acid medium. These energetic conditions probably promoted breaking of PUFA double bond, contributing to its degradation. In contrast, the samples analyzed by AOAC 996.06 GC/FID method were hydrolyzed with HCL $8.3 \mathrm{~mol} \mathrm{~L}^{-1}$ and heated at a temperature lower than $80{ }^{\circ} \mathrm{C}$. This milder procedure probably helped to preserve fatty acids molecules. The GC/FID AOAC 996.06 method gave values close to the reference samples means for all analytes evaluated (Figure 2, Table 3).

\section{Commercial chocolate biscuit}

The analyzed chocolate biscuit sample was manufactured with partially hydrogenated vegetable fat (PHVF). The TF contents determined by the different procedures diverged $(\mathrm{p}<0.05)$ only when Bligh and Dyer method was computed (Table 4). This method produced the lowest values of TF and fatty acids. Figure 3 presents the dispersion values of the TF and FA by different fat extraction methods, compared with the reference values declared on the label of the commercial chocolate biscuit. The variability was greater than $20 \%$ in some cases.

When the extraction followed the Bligh and Dyer or Soxhlet methods, results showed no significant difference $(p>0.05)$ between calculation methods using internal standard (IS) and normalization (Norm) with theoretical conversion factors (0.956). Nonetheless, in the case of Bligh and Dyer method, solvents are toxic and the method 
Table 4. TF, SFA, PUFA and TFA concentration values in commercial chocolate biscuit. Values for the different fat extraction methods as well as those described on the product label. For each extraction method, results obtained by distinct calculation modes (using internal standard or normalization)

\begin{tabular}{|c|c|c|c|c|c|c|c|c|c|}
\hline & & \multirow[b]{2}{*}{$\begin{array}{c}\text { Reference on } \\
\text { sample label }\end{array}$} & \multicolumn{7}{|c|}{$\mathrm{n}_{2}=5$} \\
\hline & & & $\begin{array}{l}\text { AOAC } \\
966.06\end{array}$ & \multicolumn{2}{|c|}{ AOAC 963.15} & \multicolumn{2}{|c|}{ Soxhlet } & \multicolumn{2}{|c|}{ Bligh and Dyer } \\
\hline \multirow{4}{*}{$\begin{array}{l}\text { TF } \\
\text { (g/100 g sample) }\end{array}$} & Mean & 22.00 & $20.92^{\mathrm{a}}$ & \multicolumn{2}{|c|}{$21.33^{\mathrm{a}}$} & \multicolumn{2}{|c|}{$21.06^{\mathrm{a}}$} & \multicolumn{2}{|c|}{$18.54^{\mathrm{b}}$} \\
\hline & SD & - & 0.40 & \multicolumn{2}{|c|}{0.37} & \multicolumn{2}{|c|}{0.27} & \multicolumn{2}{|c|}{0.57} \\
\hline & $\%$ RSD & - & 1.92 & & & \multicolumn{2}{|c|}{1.26} & \multicolumn{2}{|c|}{3.08} \\
\hline & & & & IS & Norm & IS & Norm & IS & Norm \\
\hline \multirow{4}{*}{$\begin{array}{l}\text { SFA } \\
\text { (g/100 g sample) }\end{array}$} & Mean & 13.30 & $13.32^{\mathrm{b}}$ & $12.80^{\mathrm{b}}$ & $13.96^{\mathrm{a}}$ & $13.23^{\mathrm{b}}$ & $13.48^{\mathrm{a}, \mathrm{b}}$ & $10.96^{\mathrm{c}}$ & $11.30^{\mathrm{c}}$ \\
\hline & SD & - & 0.15 & 0.47 & 0.29 & 0.30 & 0.16 & 0.18 & 0.33 \\
\hline & $\% \mathrm{RSD}$ & - & 1.13 & 3.66 & 2.06 & 2.29 & 1.20 & 1.54 & 2.90 \\
\hline & & & & IS & Norm & IS & Norm & IS & Norm \\
\hline \multirow{4}{*}{$\begin{array}{l}\text { PUFA } \\
\text { (g/100 g sample) }\end{array}$} & Mean & 1.00 & $0.94^{\mathrm{a}}$ & $0.80^{\mathrm{b}}$ & $0.87^{\mathrm{b}}$ & $0.82^{\mathrm{b}}$ & $0.83^{\mathrm{b}}$ & $0.80^{\mathrm{b}}$ & $0.86^{\mathrm{b}}$ \\
\hline & SD & - & 0.09 & 0.09 & 0.09 & 0.05 & 0.02 & 0.07 & 0.03 \\
\hline & $\%$ RSD & - & 9.94 & 11.03 & 9.84 & 5.49 & 2.14 & 8.55 & 4.01 \\
\hline & & & & IS & Norm & IS & Norm & IS & Norm \\
\hline \multirow{3}{*}{$\begin{array}{l}\text { TFA } \\
\text { (g/100 g sample) }\end{array}$} & Mean & 3.90 & $3.06^{\mathrm{b}, \mathrm{c}}$ & $2.86^{\mathrm{b}, \mathrm{c}}$ & $3.10^{\mathrm{b}}$ & $3.31^{\mathrm{a}}$ & $3.30^{\mathrm{a}}$ & $2.72^{\mathrm{c}}$ & $2.89^{\mathrm{b}, \mathrm{c}}$ \\
\hline & SD & - & 0,19 & 0.16 & 0.12 & 0.17 & 0.09 & 0.27 & 0.15 \\
\hline & $\%$ RSD & - & 6.22 & 5.59 & 3.92 & 5.14 & 2.81 & 9.83 & 5.27 \\
\hline
\end{tabular}

a,b,c Means with the same letter in the same line are not significantly different ( $\mathrm{p} \leq 0.05)$. Theoretical factor for normalization (Norm): 0.956 . IS: internal standard FAME 13:0. SD: standard deviation RSD: relative standard deviation...n ${ }_{2}$ : number of repetitions.

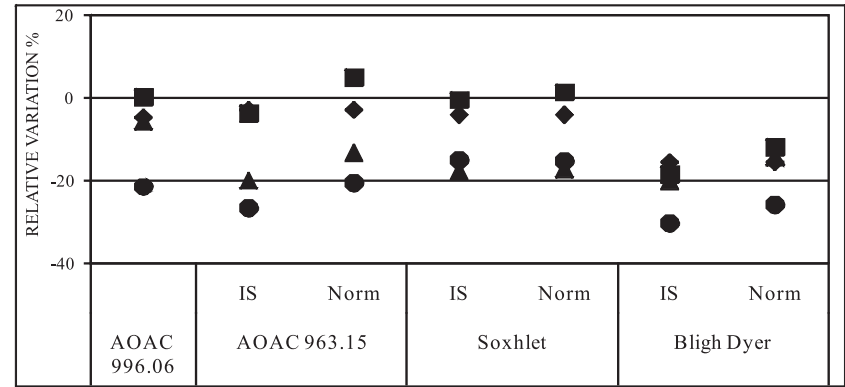

Figure 3. Relative percentage variations of experimental values of commercial chocolate biscuit sample, from different procedures, to the reference values (zero ordinate) of total fat $\bullet$, saturated (SFA) $\mathbf{\bullet}$, polyunsaturated (PUFA) $\triangle$ and trans fatty acid (TFA) •. IS: internal standard, FAME 13:0. Norm: normalization. AH: acid hydrolysis(AOAC 996.06; AOAC 963.15)

provided the lowest lipid recovery. ${ }^{8,11,13}$ The results by Soxhlet method showed the lowest dispersion for TF and FA $(n=5)$.

Figure $2 \mathrm{~S}$, supplementary material, presents the FAME chromatogram of chocolate biscuit fat by GC/FID analysis, in which the region of cis/trans 18:1 isomers is expanded. A number of 18:1 trans isomers are present in PHVF, so both content and variety of TFA are greater in this sample than in milk fat (Figures $1 \mathrm{~S}$ and $2 \mathrm{~S}$ ). The total trans fatty acids, determined by different methods, was lower than the value informed on the nutrition facts label, and the variability of some values was greater than $20 \%$ (beyond the tolerance range accepted by Brazilian legislation). ${ }^{4}$ The values may have diverged as a result of the analytical methods, as well as the variation of TFA present in PHVF used in the manufacture of the biscuits. Since PHVF may present large variation about TFA contents, ${ }^{33}$ manufacturers must care about decreasing the level of such contents in foods along with monitoring their concentration in the raw materials.

\section{Vanilla pudding sample}

Table 5 presents the results of TF and FA obtained from vanilla pudding sample. This sample had the lowest content of fat (about $6 \%$ ) in comparison with the other samples analyzed.

Total fat content determined by chloroform/methanol extraction method (Folch, Lees and Stanley ${ }^{26}$ ) was the lowest, and showed significant difference from the results of others methods. These results were probably consequence of interference caused by the high content of sugar present in the sample.

The gravimetric methods with previous acid hydrolysis $(\mathrm{AH})$, especially that based on the AOAC 963.15 method, resulted in the highest TF rates, as well as in the widest dispersions (\% RSD) of PUFA and TFA (Table 5).

Concerning PUFA values, they were overestimated for vanilla pudding (Table 5), a sample with a higher proportion of PUFA than the other ones. Variance analysis and Tukey test showed that the employment of theoretical FID correction factor (TCF) in the quantitative calculation had a distinct influence (5\% significance) in the final PUFA values when compared with the results obtained by the use of the empirical FID correction factor (ECF) (Table 5). The experimental determination of FID correction factors for PUFA by means of calibrations with pools of standards, as recommended in AOAC 996.06 method, ${ }^{6}$ was not accurate, because commercial PUFAs standards are unstable. ${ }^{34}$ More adequate results for PUFA in foodstuffs probably should be obtained employing theoretical FID correction response factors (TCF) in calculation of PUFA, as recommended in AOCS methods. ${ }^{17}$

Taken into account all analyzed food samples, the total fat and, consequently, the fatty acids values depended on the analytical method. The gravimetric methods with acid hydrolysis (AH), especially that based on the AOAC 963.15 method, resulted in the highest TF 
Table 5. TF, SFA, PUFA and TFA concentration values in vanilla pudding reference sample (AOCS nutritional labeling series 2004/2005). Values for the different fat extraction methods as well as those described in the reference study are presented. For each extraction method, results obtained by distinct calculation modes (using internal standard or normalization) and FID correction factors (theoretical -TCF- or empirical -ECF) are displayed

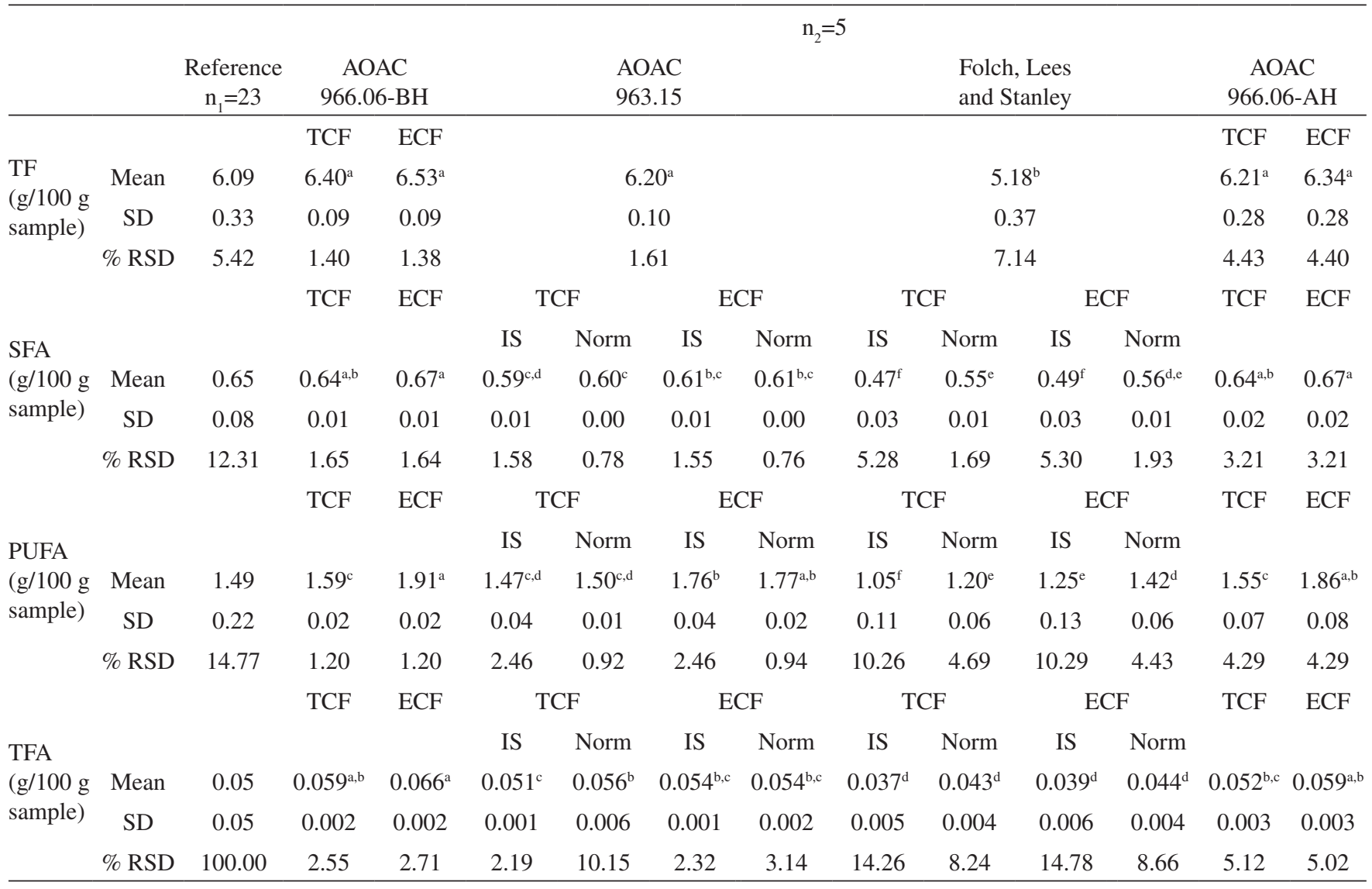

a,b,c,d,e,f Means with the same letter in the same line are not significantly different ( $\mathrm{p} \leq 0.05$ ). Theoretical factor for normalization (Norm): 0.956. IS: internal standard FAME 13:0. SD: standard deviation RSD: relative standard deviation: $n_{1}$ : number of laboratories. $n_{2}:$ number of repetitions. TCF: relate to EMAG 16:0. ECF: relate to FAME 13:0. AH: acid hydrolysis. BH: basic hydrolysis.

rates, as well as in the widest dispersions (\% RSD) of PUFA and TFA The Bligh and Dyer, ${ }^{25}$ the Folch, Lees and Stanley ${ }^{26}$ and Roese Gottlieb $^{6}$ methods presented the lowest TF values for the majority of the samples. The most probable cause being the requirement of several extraction steps for an adequate total fat recovery (Tables 1-5 and Figures 1-3).

A comparison of analysis time and solvent volume employed on fat extraction in each procedure was made. Concerning the analysis time, the Bligh and Dyer method was the fastest and the solvent volumes were the smallest. However, this method has limitations, mentioned earlier, namely the use of toxic solvents and its low fat recovery in some cases. AOAC 996.06, ${ }^{6}$ with the modification implemented in this work, was fast. It spent the same time for Bligh and Dyer procedure and employed lower toxicity solvents such as petroleum ether and diethyl ether.

\section{Evaluation of modified gas chromatographic AOAC 996.06 method for TF and FA determination}

Extraction and measurements of fat and fatty acids from a variety of food samples by AOAC 996.06 method, with the modifications introduced in this study, showed satisfactory precision for TF, SFA, PUFA and TFA. In most cases, relative standard deviation values (\% RSD) were below $5 \%$, for the analytes with concentrations above $1 \%$, as showed in Tables 1 to 5. Concerning the TFA and PUFA, the values of the dispersions were higher, especially for analytes concentrations below $1 \%$. However, all dispersions observed were similar to those presented in collaborative studies of the official methods (AOAC 996.06; AOAC 996.01; AOCS Ce 1h-05). ${ }^{6,17,20}$ AOAC 996.06 method produced, for most samples and analytes, values close to the reference samples means (Figures 1-3). On the other hand, some difficulties were observed during the experimental work. The AOAC 996.06 method was developed taking into account both the food matrices differences and the extraction principle in original gravimetric methods, but in a reduced scale. The fat content, the initial mass and non homogeneity of commercial samples could affect method performance. Although the hydrolitic conditions employed in AOAC 996.06 are milder than in other hydrolitic methods, some reactive sites of samples, such as PUFA, could be affected and produce artifacts.

Satisfactory recoveries were verified for studied food samples (97 to 103\%), when the Hartman and Lago methylation procedure was adapted to the AOAC 996.06 method. This methodology can advantageously substitute the official AOAC method for preparation of FAMEs, since it abolishes the execution of toxic methanolic borum trifluoride $\left(\mathrm{BF}_{3}\right)$ methylation, which may lead to the formation of secondary byproducts ${ }^{35}$ and requires longer time and higher temperatures to be completed. Through the association of modified AOAC 996.06 method and Hartman and Lago methylation, both time and solvents are spared. Moreover the employed solvents and chemicals are less toxic. TF determination is achieved by mathematical calcu- 
lation, after FAs are determined by GC/FID, considerably shortening analysis time. The method can be applied to most alimentary matrices once the extraction of both free and linked lipid molecules is made possible by means of previous hydrolysis. Additionally, Codex Alimentarius Committee has proposed the endorsement of the AOAC 996.06 method for TF and FA determination for nutritional labeling purposes, in trade disputations between countries. ${ }^{36}$

\section{CONCLUSIONS}

The studied methods for total fat and fatty acid quantization in different products (dairy products, vanilla pudding and chocolate biscuit) reinforced that results depend on several variables established in each procedure, such as solvent extraction, pre-treatment, features of sample (fat and moisture content) and FA quantization by normalization or with internal standards. Significant differences $(\mathrm{p}<0.05)$ were observed among the results by the different methods in most cases. Taken into account the mean reference values, the results varied more than $20 \%$ in some cases (mainly for TFA), which is above the accepted by the Brazilian technical regulation over nutritional labeling. These data denote, therefore, the necessity of analytical method standardization among Brazilian laboratories and the revision of definitions and tolerancies established in law for the evaluation of the nutritional labeling. These implementations will contribute to uniform consumer information and facilitate the trade of Brazilian products.

Comparing the gravimetric and gas chromatographic AOAC 996.06 methods, the last one with modifications, revealed both satisfactory accuracy and precision in TF, SFA and TFA quantization ( $\%$ RSD $<5 \%$ for analytes with concentrations above $1 \%$ ). The procedure was fast and employed low-toxicity solvents, in smaller volumes, being thus a viable methodology to be adopted in Brazil for nutritional labeling purposes.

\section{SUPPLEMENTARY MATERIAL}

Available in http://quimicanova.sbq.org.br, in format PDF, free access.

\section{ACKNOWLEDGEMENTS}

Authors are grateful to Fundação de Amparo à Pesquisa do Estado de São Paulo (FAPESP) for the financial support.

\section{REFERENCES}

1. Hawke, C.; Nutrition labels and health claims: the global regulatory environment, World Health Organization: Geneva, 2004.

2. Organización Mundial de La Salud; Dieta, nutrición y prevención de enfermedades crónicas, Serie de informes técnicos/916, OMS: Ginebra, 2003.

3. Mozaffarian, D.; Katan, M.B.; Ascherio, A.; Stampfer, M.J.; Willett, W.C.; New Engl. J. Med. 2006, 354, 16071.

4. Ministério da Saúde, Secretaria de Vigilância Sanitária; Resolução-RDC $n^{\circ} 360$, de 23/12/ 2003, Dispõe sobre o Regulamento Técnico sobre Rotulagem Nutricional de Alimentos Embalados, Diário Oficial da União 26/12/2003, Seção 1:33-4

5. Mancini-Filho, J.; Takemoto, E.; Aued-Pimentel, S. In Vigilância sanitária: tópicos sobre legislação e análise de alimentos; AlmeidaMuradian, L. B.; Penteado, M. V. C., eds.; Guanabara Koogan: Rio de Janeiro, 2007, p. 81-107.
6. Official Methods of Analysis of AOAC; $18^{\text {th }}$ ed., AOAC International: Gaithersburg, 2005.

7. Lago, R.C.; Piombo, G.; Antoniassi, R.; IUPAC/AOCS Workshop on fats oils and oilseeds, analysis and production, Tunis, Tunísia, 2004.

8. http://www.lipidlibrary.co.uk/topics/extract/index.htm, acessada em Abril 2007.

9. Kirk, R.S.; Sawer, R.; Egan, H.; Composición y Análisis de Alimentos de Pearson, $2^{\text {nd }}$ ed., Compania Editorial Continental SA: México, 1996.

10. Instituto Adolfo Lutz; Métodos físico-químicos para análise de alimentos, $4^{\mathrm{a}}$ ed., ANVISA: Brasília, 2005.

11. Pérez-Palacio, T.; Ruiz, J.; Martin, D.; Murial, E.; Antequera, T.; Food Chem. 2008, 110, 1025.

12. Carpenter, D. M.; Ngeh-Ngwainbi, J.; Lee S. In Methods of analysis for nutritional labeling; Carpenter, D. E; Sullivan, D. M., eds.; AOAC International: Arlington, 1993, p. 85-104.

13. Iverson, S. J.; Lang, S. L. C.; Cooper, M. H.; Lipids 2001, 36,1283.

14. Mc Cance, Widdowson's eds.; The composition of food, $6^{\text {th }}$ ed., Royal Society of Chemistry: Cambridge, 2002

15. Ackman, R. G..; Sipos, J. C.; J. Am. Oil Chem. Soc.1964, 41, 377

16. Bannon, C. D.; Graske, J. D.; Hillker, A. E.; J. Am. Oil Chem. Soc. 1986, 63,105 .

17. Official methods and recommended practices of the AOCS; $5^{\text {th }}$ ed, Champaign (IL): AOCS; Additions and revisions 1999-2006. Method Ce 1h-05.

18. Federal Register, Washington, Food and Drug Administration; Food labeling: mandatory status of nutrition labeling and nutrient content revision, format for nutritional label. Part 101- Food labeling. 1993, 58, p. 2175-2205.

19. De Vries, K. L.; Grof, L.; Martin, B., Cernohous, K.; Patel, H.; JAOAC Int. 1999, 82,1146.

20. Rozena, B.; Mitchell, B.; Winters, D.; Kohn, A.; Sullivan, D.; Meinholz, E.; JAOAC Int. 2008, 92, 92.

21. Aued-Pimentel, S.; Tese de doutorado, Secretaria de Estado da Saúde de São Paulo, Brasil, 2007.

22. Ali, L. H.; Angyal, G.; Weaker, C. M.; Rader, J. I.; Food Chem. 1997, $58,149$.

23. Rader, J. I.; Anguila, G.; O’Dell, R. G.; Weaver, C. M.; Sheppard, A. J.; Bueno, P.; Food Chem. 1995, 54, 419.

24. Satchithanandam, S.; Carolyn, J.; Oles Spease, C. J.; Brandt, M. M.; Yurawecz, M. P.; Rader, J. I.; Lipids 2004, 39, 11.

25. Bligh, E. G.; Dyer, W. J.; Can. J. Biochem. Physiol. 1959, 37, 911.

26. Folch, J.; Lees, M.; Stanley, G. H. S.; J. Biol. Chem. 1957, 226, 497.

27. Satchithanandam, S.; Fritsche, J.; Rader, J. I.; J. AOAC Int. 2001, 84, 805.

28. Hartman, L.; Lago, R. C. A.; Lab. Prac. 1973, 22, 475.

29. Maia, E. L.; Rodrigues-Amaya, D.; Rev. Inst. Adolfo Lutz 1993, 53, 27.

30. Ayres, M.; Ayres, M. J. R.; Ayres, D. L.; Santos, A. S.; BioEstat. 3.0. Aplicações estatísticas nas áreas das ciências biológicas e médicas, Sociedade Civil Mamirauá: Brasília, 2003.

31. http://monographs.iarc.fr/ENG/Preamble/CurrentPreamble.pdf, acessada em Outubro 2007.

32. Posati, L. P.; Kinsella, J. E.; Watt, B. K.; J. Am. Diet Assoc. 1975b, 67, 111.

33. Tarrago-Trani, M. T.; Phillips, K. M.; Lemar, L. E.; Holden, J. M.; J. Am. Diet. Assoc 2006, 106, 867.

34. Schreiner, M.; J. Chromatogr., A 2005, 1095, 126

35. http://www.lipid.co.uk/infores/topics/methests/index.htm, acessada em Outubro 2004.

36. Codex Alimentarius Commission; Report of the the twenty eighth session of the Codex Committee on methods of analysis and sampling. Budapest, Hungary. 5-9 March, 2007. 


\section{COMPARISON OF GAS CHROMATOGRAPHIC AND GRAVIMETRIC METHODS FOR QUANTIZATION OF TOTAL FAT AND FATTY ACIDS IN FOODSTUFFS}

Sabria Aued-Pimentel*, Mahyara Markievicz Mancio Kus, Edna Emy Kumagai, Valter Ruvieri e Odair Zenebon Divisão de Bromatologia e Química, Instituto Adolfo Lutz, Av. Dr. Arnaldo, 355, 01246-902 São Paulo - SP, Brasil

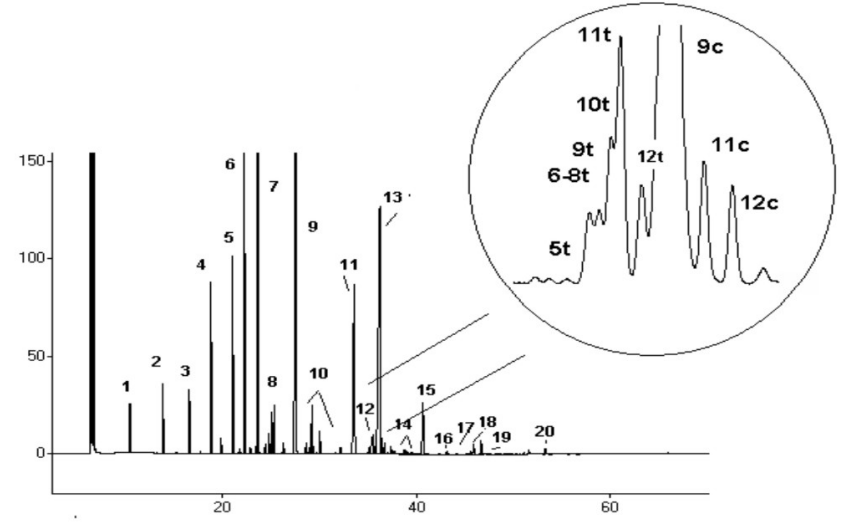

Figure 1S. FAME chromatogram of powder milk fat by means of GC/FID analysis. 1. 4:0; 2. 6:0; 3. 8:0; 4.10:0; 5.12:0; 6.13:0 (internal standard); 7. 14:0; 8.14:1c; 9.16:0; 10.16:1; 11.18:0; 12.18:1t (main trans-vacenic); 13.18:1c; 14.18:2t; 15.18:2c/c; 16. 20:0; 17.20:1; 18.18:3c/c/c; 19.CLA, 18:2 9c,11t; 20 20:4. Expansion: partial chromatogram of $18: 1$ cis/trans isomers region

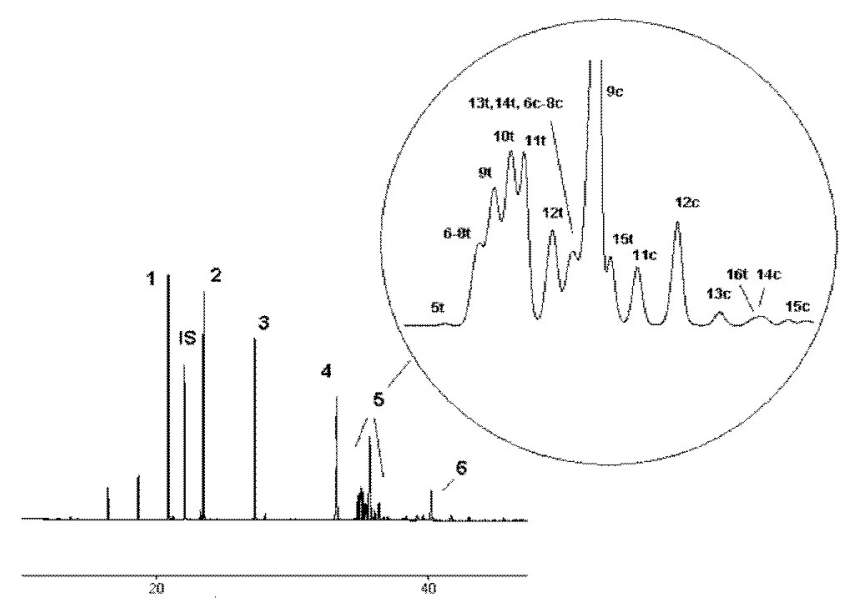

Figure 2S. FAME chromatogram of chocolate biscuit fat by means of GC/ FID analysis. 1.12:0; IS.13:0 (internal standard); 2.14:0; 3.16:0, 4.18:0 5.18:1 (cis/trans isomers); $6.18: 2 \mathrm{c} / \mathrm{c}$. Expansion: partial chromatogram of 18:1 cis/trans isomers region 